\title{
The effects of gonadectomy and chronic testosterone suppletion on the autoshaped response of male and female Wistar rats
}

\author{
ANNEMIEKE VAN HEST and FRANS VAN HAAREN \\ Netherlands Institute for Brain Research, Amsterdam, The Netherlands
}

\begin{abstract}
Different groups of intact, gonadectomized, and gonadectomized plus testosterone-treated male and female rats were exposed to an autoshaping procedure in order to investigate the contribution of gonadal hormones to the behavioral differences between intact male and female rats observed in these procedures. Stimulus presentation (5-sec extension of a lever and illumination of the stimulus light above the lever) occurred on a variable-time 25-sec schedule and was followed by the presentation of response-independent food. Intact, castrated, and testosterone-treated males showed more signtracking than intact or gonadectomized females. Testosterone-treated females contacted the CS more often than did intact females. Differences between groups of males were not observed. Between-sex comparisons revealed that intact and gonadectomized males responded more frequently than intact or gonadectomized females; differences between testosterone-treated males and females were not observed. As such, the results of the present experiment suggest that testosterone may play an important role in mediating sex differences in the acquisition of autoshaped responding.
\end{abstract}

Members of different species have been shown to approach and contact a signal (CS) that reliably precedes the presentation of response-independent food (US; see Brown \& Jenkins, 1968, on autoshaping). The frequency of such autoshaped responses (also referred to as signtracking; see Hearst \& Jenkins, 1974) has been shown to depend on the relative duration of the CS (Gibbon, Baldock, Locurto, Gold, \& Terrace, 1977), the frequency of US presentation in the absence of the CS (Gamzu \& Williams, 1973), and the percentage of CSs followed by US presentation (Davey \& Cleland, 1982a). The form of the autoshaped response depends upon qualitative properties of the US (Davey \& Cleland, 1982b, 1984; Davey, Phillips, \& Cleland, 1981; Jenkins \& Moore, 1973). Subjects not only exhibit signtracking behavior, but also engage in behavior directed towards the site of US presentation in autoshaping experiments (goaltracking; see Hearst \& Jenkins, 1974). The frequency of goaltracking behavior has been demonstrated to depend on the modality of the CS and on specific parameters of the experimental environment (Cleland \& Davey, 1983), as well as on the variability of the intertrial interval (ITI; see van Haaren, van Hest, \& van de Poll, 1987; van Hest, van Haaren, Kop, \& van der Schoot, 1986).

It has recently been observed that sign- and goaltracking behavior in autoshaping procedures may also vary as a function of the subjects' gender. Van Haaren et al.

This research was conducted while Annemieke van Hest was supported by a grant from the Dutch Organization for the Advancement of Basic Research (ZWO 560-258-024) awarded to Frans van Haaren. Correspondence may be addressed to A. van Hest, Netherlands Institute for Brain Research, Meibergdreef 33, 1105 AZ Amsterdam, The Netherlands.
(1987) manipulated the duration and variability of the ITI in a discriminated autoshaping procedure and observed male Wistar rats to be more likely than females to contact the CS at higher frequencies, while goaltracking was observed at higher rates in females than in males. Females were also more likely than males to adjust to changes in experimental parameters when experimental contingencies were reversed.

Differences between the sexes in nonreproductive behavior have been shown to depend not only on specific parameters of the experimental procedures in which they are investigated (see, e.g., van Haaren \& van de Poll, 1984a, 1984b, 1986; van Haaren et al., 1987; van Haaren, van Hest, \& van de Poll, 1988; van Hest, van Haaren, \& van de Poll, 1987a, 1987b, in press), but also on the presence or absence of gonadal hormones (for review, see Beatty, 1979; cf. Heinsbroek, van Haaren, Zantvoord, \& van de Poll, 1987; van Hest, van Kempen, van Haaren, \& van de Poll, 1988). The present experiment was thus designed to investigate the effects of gonadectomy on autoshaped responding in male and female Wistar rats. Because of the fact that some behavioral differences between the sexes have been shown to be critically dependent on the presence of the male gonadal hormone testosterone or its metabolites (Beatty, 1979), different groups of intact, gonadectomized, and gonadectomized plus testosterone-treated male and female rats were used in the experiment.

\section{METHOD}

Subjects
Twenty-four male and 24 female Wistar rats were obtained from
Animal House, TNO (Zeist, the Netherlands) when they were 9 weeks 
old. They were housed in group cages (4 same-sex subjects to a cage) under a reversed light:dark cycle (lights on 3:30 p.m.-3:30 a.m.) upon arrival in the laboratory. Sixteen males and 16 females were gonadectomized under light Hypnorm $(0.02 \% ; 0.05 \mathrm{ml})$ anesthesia when they were 10 weeks old. Half of the gonadectomized subjects simultaneously received a subcutaneous testosterone implant in the neck region $(2.0 \mathrm{~cm}$ silastic tubing loaded with testosterone). Two weeks before the start of experimentation, the subjects were food-deprived on a 23-h schedule (Hurwitz \& Davis, 1983) in order to maintain body weight at approximately $85 \%$ of free-feeding body weight. Water was always available in the home cages. Experimentation started when the subjects were 12 weeks old.

\section{Apparatus}

The experiments took place in eight locally constructed rat chambers, which have been described in detail elsewhere (van Haaren et al., 1987).

\section{Procedure}

Adaptation. Six experimental groups had been formed, each consisting of 8 subjects. However, due to intermittent equipment failure in one of the experimental chambers and to the death of one of the male subjects, the following groups of males and females were used in the experiment: intact (INT: 6 males, 7 females), gonadectomized (GON: 7 males, 7 females), and gonadectomized plus testosterone implant (TEST: 7 males, 7 females). All the subjects were adapted to the experimental chamber and the sound of the pellet dispenser for one 20min session, during which unsignaled food presentations (45-mg Bio-Serve food pellets) were scheduled to occur on a variable time (VT) 30 -sec schedule. The houselight was illuminated and the levers were retracted from the experimental chamber during this session.

Autoshaping. All groups were exposed to an autoshaping procedure for 20 sessions. The houselight was illuminated at the start of each session. The left lever (CS) was presented on a VT 25 -sec schedule. CS presentations were accompanied by illumination of the stimulus light, which was located directly above the lever. The stimulus was extinguished and the lever retracted from the chamber after $5 \mathrm{sec}$ of CS presentation. Response-independent food (US) was presented immediately upon retraction of the lever from the chamber, irrespective of the subjects' behavior. All US presentations were accompanied by a 1.0 -sec illumination of the light in the food tray. Sessions ended after 40 CS-US pairings had been presented; they were run 5 days a week (Monday through Friday), during the subjects' dark hours.

\section{RESULTS}

A two-way analysis of variance (ANOVA) involving the factors group (G) and sessions (SES; four blocks of five sessions, repeated measures) was conducted on the percentage of CS presentations with at least one response, on the response rates (responses/min) during CS presentation, and on goal-directed activity (food tray entries/min during CS presentation). Rate measures were logtransformed, while percentage scores were arc-sine transformed before analysis to increase homogeneity of variance (Winer, 1971).

Figure 1 shows the percentage of CS presentations with at least one CS contact. ANOVA revealed that the percentage of CS presentations with at least one response differed between groups [G: $F(5,35)=5.16$ ], and increased over sessions [SES: $F(3,105)=81.62$; both $p s<.01]$. A significant $G \times$ SES interaction effect $[F(15,105)=2.18, p<.05]$ suggested that prolonged training differentially affected the behavior of the different groups of subjects. Pairwise comparisons between groups were then made by means of separate ANOVAs. Differences between INT and GON females, or between

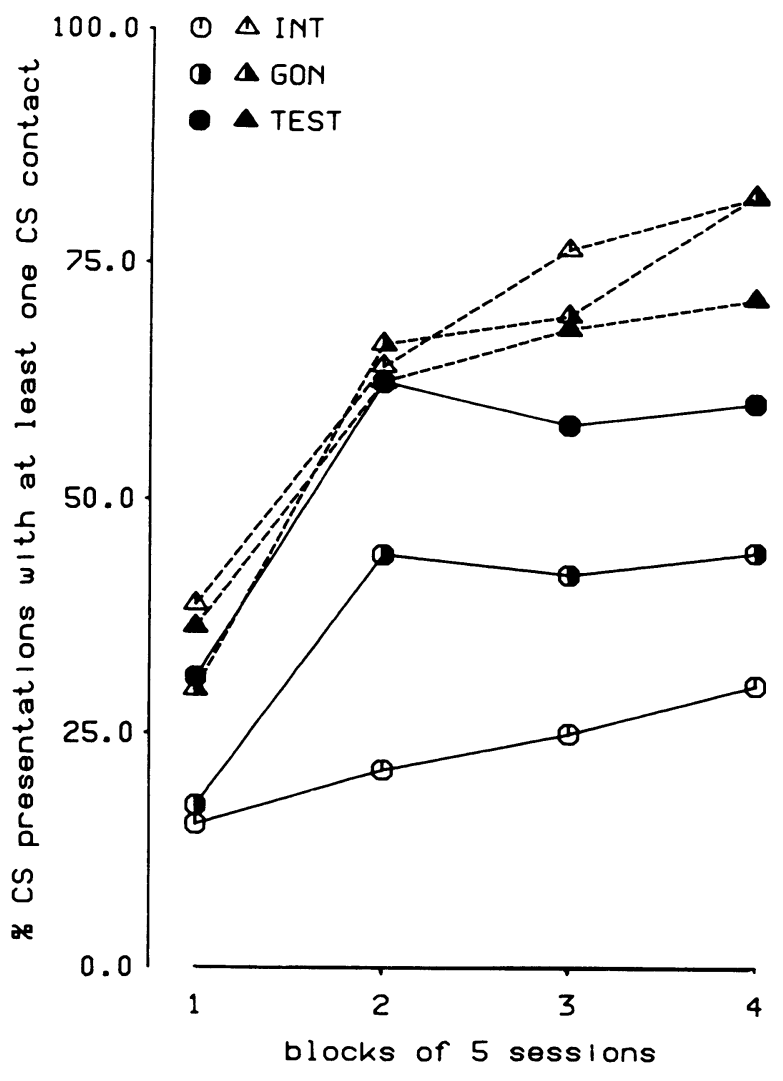

Figure 1. The percentage of $\mathrm{CS}$ presentations with at least one CS contact response for the different groups of subjects averaged over five consecutive sessions. Males and females are indicated by triangles and circles, respectively.

GON and TEST females were not observed. However, TEST females contacted the CS on more trials than INT females $[F(1,12)=5.55, p<.05]$. Differences between groups of males were not observed. Between-sex comparisons showed that INT females contacted the CS less often than INT, GON, or TEST males [INT: $F(1,11)=$ 15.78 , GON: $F(1,12)=13.62$, TEST: $F(1,12)=15.06$, all $p s<.01]$. GON females also responded on fewer trials than males [INT: $F(1,11)=8.54$; GON: $F(1,12)$ $=6.60$; TEST: $F(1,12)=7.06$; all $p s<.05]$, but differences between TEST females and any of the groups of males were not observed.

Figure 2 shows the response rates (responses/min) during CS presentation for the different groups of subjects. ANOVA similar to the one used to analyze the percentage of CS presentations with at least one response showed that contact rates differed between groups [G: $F(5,35)=$ $4.76, p<.01$ ] and increased over sessions [SES: $F(3,105)=61.59, p<.01]$. Differences between INT and GON females, or between GON and TEST females, were not observed. However, TEST females responded at higher rates than INT females $[F(1,12)=6.33$, $p<.05]$. Differences between groups of males were not observed. Between-sex comparisons showed that response rates of INT females were lower than those of males [INT: 
$F(1,11)=20.24 ;$ GON: $F(1,12)=15.49 ;$ TEST: $F(1,12)$ $=19.18$; all $p \mathrm{~s}<.01]$. GON females responded less frequently than INT males [INT: $F(1,11)=5.58, p<.05$ ], but differences between GON females and GON males, or between GON females and TEST males, just failed to reach significance $[\mathrm{GON}: F(1,12)=4.11$; TEST: $F(1,12)$ $=4.19$; both $p s=.06$ ] . Differences between TEST females and any of the groups of males were not observed.

Figure 3 shows goal-directed activity (food tray entries/min) during CS presentation for the different groups of subjects. ANOVA showed that goal-directed activity did not differ between the groups $[F(5,35)=1.01$, n.s. $]$, but decreased as training progressed $[F(3,105)=40.92$, $p<.01]$. A significant $\mathrm{G} \times \mathrm{SES}$ interaction $[F(15,105)$ $=2.20, p<.01]$ suggested that goal-directed activity decreased differentially for the different groups. However, none of the pairwise comparisons between groups reached statistical significance.

\section{DISCUSSION}

Gonadal hormones have been shown to affect behavioral responses to environmental stimuli in tests for sexual, agonistic, and maternal behavior (Beatty, 1979). The observed behavioral differences between the sexes when male and female Wistar rats are exposed to different foodmotivated operant learning tasks suggest that these behaviors may also functionally be altered by the presence or absence of gonadal hormones (Heinsbroek et al., 1987; van Haaren et al., 1987, 1988; van Hest et al., 1987a, 1987b, in press; van Hest, van Kempen, van Haaren, \& van

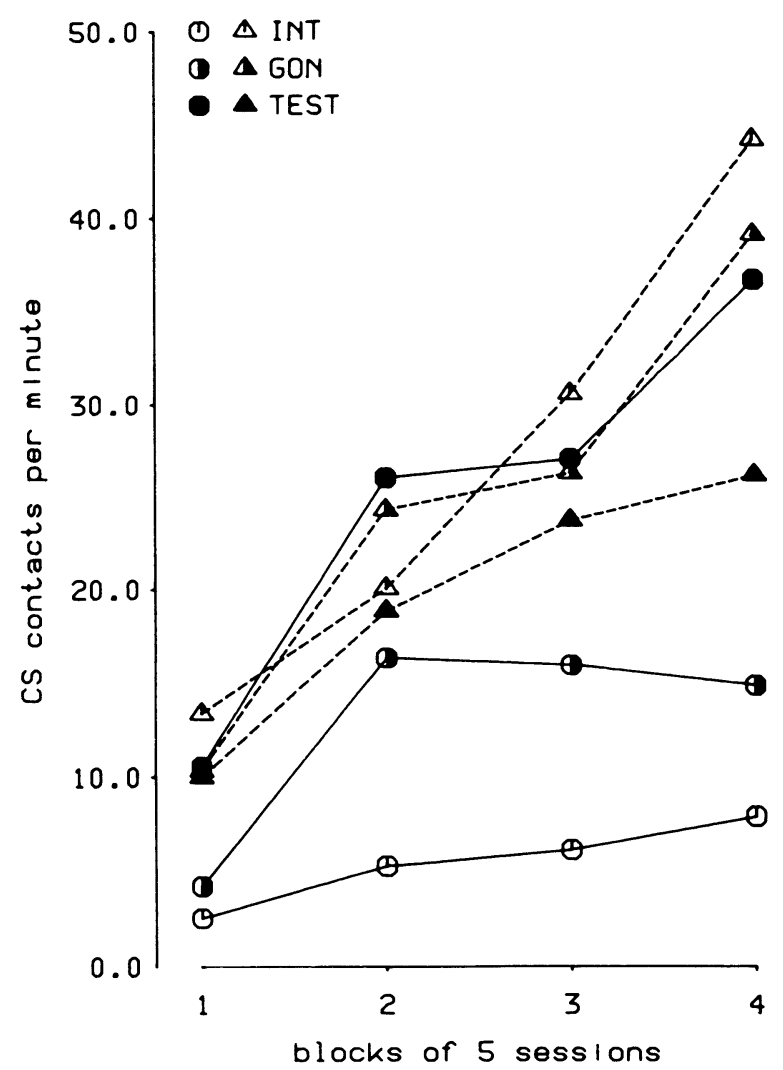

Figure 2. CS contact rates (CS contacts per minute) for the different groups of subjects averaged over five consecutive sessions. Males and females are indicated by triangles and circles, respectively.

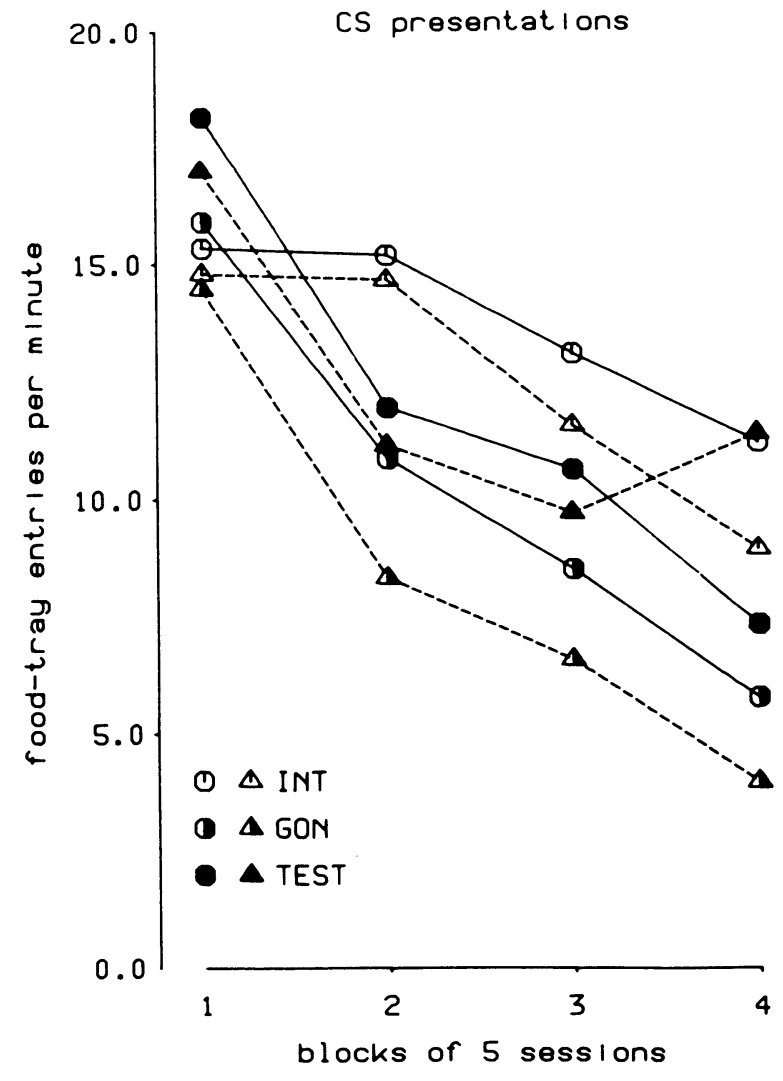

Figure 3. Goaltracking behavior (tray entries per minute) during CS presentation for the different groups of subjects averaged over five consecutive sessions. Males and females are indicated by triangles and circles, respectively.

de Poll, 1988). The present experiment showed that intact male Wistar rats were more likely than intact females to contact a lever that was presented immediately before the delivery of the US. Males also contacted the lever more frequently than females once the initial contact had occurred. As such, these results confirm those previously observed in other experiments (van Haaren et al., 1987). Preexperimental treatment of males (intact, castrated, or castrated plus chronically testosteronetreated) did not result in differences among these three groups in signtracking behavior. Ovariectomy of females also did not result in signtracking behavior different from that of intact females, but ovariectomized females which also received a testosterone implant were more likely than intact females to contact the lever at higher rates. Between-sex comparisons of the different groups revealed behavioral differences when intact and gonadectomized subjects were compared, but not between gonadectomized plus testosterone-treated males and females.

Manipulation of gonadal hormones produced seemingly conflicting evidence with respect to the effects of testosterone on behavior. Chronic testosterone suppletion in ovariectomized females resulted in autoshaped behavior similar to that of males. However, the results of the present experiment also showed that castration failed to influence the males' behavior. It could be argued that the absence of behavioral differences between the groups of intact and castrated males in the present experiment might be a function of the time delay between surgery and exposure to the experimental contingencies. It has previously been observed that some of the behavioral effects of testosterone may persist long after the hormone itself has disappeared from the circulation (Gray, Rickwood, Drewett, \& Dunne, 1977).

However, an alternative explanation must be considered. Gonadal hormones may modulate behavior in two distinct ways (Leshner, 1978, 1979), either organizationally or activationally. Organizational effects refer to the permanent and irreversible effects on adult behavior of the 
hormonal state during a critical period early in maturation. Hormones present early in development may produce lasting changes in the functioning of the adult endocrine system and may permanently alter the sensitivity of specific neuronal sites to hormones circulating in adulthood. Activational effects of gonadal hormones on behavior refer to the transient effects of hormonal status at the time a behavior occurs on the intensity or form of that particular behavior. Sexually dimorphic behaviors may be influenced by both organizational and activational actions of gonadal hormones. Obviously, testosterone suppletion in ovariectomized females resulted in behavior that greatly resembled that of the groups of males. Although these data suggest that testosterone plays an important role in determining the difference between males and females in autoshaping procedures, it could also be argued that the absence of the female hormones estrogen and progesterone plays an important role too. However, because of the fact that behavioral differences between intact and gonadectomized females were not observed, this interpretation seems less likely than one which emphasizes the role of testosterone. The absence of behavioral differences among groups of males, and the finding that testosterone masculinizes the behavior of females, suggests that both organizational (as in the case of males) and activational (as in the case of females) effects of testosterone on autoshaped behavior must be considered.

In summary, the results of the present experiment in conjunction with those of other experiments support the previously suggested hypothesis (see van Haaren et al., 1987) that behavioral differences between the sexes are a conjoint function not only of the presence or absence of organizing and activating effects of gonadal hormones (Beatty, 1979), but also (and maybe most importantly) of the experimental environment in which the possible existence of such differences is investigated. The interpretation of the role of gonadal hormones in the observed behavioral differences between the sexes should thus proceed carefully, and it can only be expected to be functionally significant once behavior has been exhaustively investigated in a large number of different experimental circumstances.

\section{REFERENCES}

BEATTY, W. W. (1979). Gonadal hormones and sex-differences in nonreproductive behavior in rodents: Organizational and activational influences. Hormones \& Behavior, 12, 112-163.

Brown, P. L., \& Jenkins, H. M. (1968). Autoshaping the pigeon's keypeck. Journal of the Experimental Analysis of Behavior, 11, 1-8.

Cleland, G. G., \& Davey, G. C. L. (1983). Autoshaping in the rat: The effects of localizable visual and auditory signals for food. Journal of the Experimental Analysis of Behavior, 40, 47-56.

Davey, G. C. L., \& Cleland, G. G. (1982a). The effect of partial reinforcement on the acquisition and extinction of sign-tracking and goal-tracking in the rat. Bulletin of the Psychonomic Society, 19, 115-118.

Davey, G. C. L., \& Cleland, G. G. (1982b). Topography of signalcentered behavior in the rat: Effects of deprivation state and reinforcer type. Journal of the Experimental Analysis of Behavior, 38, 291-304.

Davey, G. C. L., Phillips, S., \& Cleland, G. G. (1981). The topography of signal-centered behaviour in the rat: The effects of solid and liquid food reinforcers. Behavioural Analysis Letters, 1, 331-337.

Gamzu, E. R., \& Willams, D. R. (1973). Associative factors underlying the pigeon's key pecking in autoshaping procedures. Journal of the Experimental Analysis of Behavior, 19, 225-232.

Gibbon, J., Baldock, M. D., Locurto, C., Gold, L., \& Terrace, H. S. (1977). Trial and intertrial durations in autoshaping. Journal of Experimental Psychology: Animal Behavior Processes, 3, 264-284.
Gray, J. A., Rickwood, L., Drewett, R. F., \& DunNe, E. (1977). Gonadal hormones and effects of partial reinforcement on appetitive behaviour in the rat. Physiology \& Behavior, 19, 41-45.

Hearst, E., \& Jenkins, H. M. (1974). Sign-tracking: The stimulusreinforcer relation and directed action. Austin, TX: The Psychonomic Society.

Heinsbroek, R. P. W., van HaAren, F., Zantvoord, F., \& Van de Poll, N. E. (1987). Acquisition of random-ratio behavior in male and female rats: Effects of gonadectomy. Physiology \& Behavior, 39, 269-272.

Hurwitz, H. M. B., \& Davis, H. (1983). Depriving rats of food: A reappraisal of two techniques. Journal of the Experimental Analysis of Behavior, 40, 211-213.

JENkINS, H. M., \& Moore, B. R. (1973). The form of the autoshaped response with food or water reinforcers. Journal of the Experimental Analysis of Behavior, 20, 163-181.

LESHNER, A. I. (1978). An introduction to behavioral endocrinology. New York: Oxford University Press.

LESHNER, A. I. (1979). Kinds of hormonal effects on behavior: A new view. Neuroscience \& Biobehavioral Reviews, 3, 69-73.

van HaAren, F., \& VAN De Poll, N. E. (1984a). The effect of a choice alternative on sex differences in passive avoidance behavior. Physiology \& Behavior, 32, 211-216.

van HaAren, F., \& VAN DE Poll, N. E. (1984b). The number of preshock trials affects sex differences in passive avoidance behavior. Physiology \& Behavior, 33, 269-272.

van HaARen, F., \& VAN De Poll, N. E. (1986). Effects of light intensity on passive avoidance behavior of male and female Wistar rats. Physiology \& Behavior, 36, 123-125.

van HaAren, F., van Hest, A., \& Van de Poll, N. E. (1987). Acquisition and reversal of a discriminated autoshaped response in male and female rats: Effects of long or short and fixed or variable intertrial interval durations. Learning \& Motivation, 18, 220-233.

van Haaren, F., van Hest, A., \& van de Poll, N. E. (1988). Selfcontrol in male and female rats. Journal of the Experimental Analysis of Behavior, 49, 201-211.

van Hest, A., van HaAren, F., Kop, P., \& van der Schoot, F. (1986). Stimulus- and feeder-directed behavior in a long-box: Effect of fixed versus variable time schedules of food presentation. Animal Learning \& Behavior, 14, 168-172.

van Hest, A., van Haaren, F., \& van de Poll, N. E. (1987a). Behavioral differences between male and female Wistar rats on DRL schedules: Effect of stimuli promoting collateral activities. Physiology \& Behavior, 39, 255-261.

van Hest, A., van HaAren, F., \& van de Poll, N. E. (1987b). Behavioral differences between male and female Wistar rats in food rewarded lever holding. Physiology \& Behavior, 39, 263-267.

van Hest, A., van Haaren, F., \& van de Poll, N. E. (in press). Perseverative responding in male and female Wistar rats: Effects of gonadal hormones. Hormones \& Behavior.

van Hest, A., van Kempen, M., van HaAren, F., \& van de Poll, N. E. (1988). Memory in male and female Wistar rats: Effects of gonadectomy and stimulus presentations during the delay interval. $\mathrm{Be}$ havioural Brain Research, 29, 103-110.

WINER, B. J. (1971). Statistical principles in experimental design. New York: McGraw-Hill Book Company.

(Manuscript received June 6, 1988.) 